\title{
Investigar-crear: por unos modos de acontecer en la investigación con arte y literatura*
}

\section{John Echavarría Cañas}

Institución Educativa Federico Sierra Arango (Bello, Antioquia)

johnjairoechavarría@hotmail.com

\section{Teresita Ospina Álvarez}

Universidad de Antioquia

teresita.ospinaalvarez@gmail.com

Recibido el: 07/21/2020

Aceptado el: 24/02/2021

Cómo citar este artículo: Echavarría Cañas, J. y Ospina Álvarez, T. (2021). Investigar-crear: por unos modos de acontecer en la investigación con arte y literatura. Calle 14: revista de investigación en el campo del arte. 16(30), pp.374-391. https://doi.org/10.14483/21450706.18307

\section{(ㄷ) (1)}

https://creativecommons.org/licenses/by/4.0/deed.es 

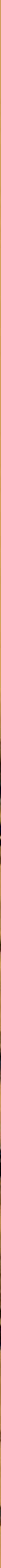


\begin{abstract}
Resumen
El presente artículo nace de la tesis doctoral Formación de subjetividades: Escrituras minográficas de los cuerpos en la ciudad, la cual está adscrita al Doctorado en Ciencias de la Educación de la Universidad de San Buenaventura - Medellín, línea de investigación: Estudios Culturales y Lenguajes Contemporáneos del grupo de investigación ESINED. En el texto nos ocupamos del proceso de contextualización epistemológica del concepto de experimentación desde autores de la filosofía de la diferencia, en entrecruces con la investigación-creación, lo cual motiva una manera de proceder metódica que indaga en otras formas de prolongar la literatura en tanto escritura de experimentación, es decir: las escrituras minográficas. Este tipo de producciones estéticas permitieron desplegar una serie de acciones metódicas para crear con los cuerpos que hicieron presencia en la ciudad de Medellín, habitando lugares existenciales para luego devenir en otros cuerpos y subjetividades.
\end{abstract}

\title{
Palabras claves
}

Ciudad; cuerpos; escrituras minográficas; experimentación e investigación-creación

\begin{abstract}
This article arises from the doctoral thesis Formation of subjectivities: Minographic writings of bodies in the city, submitted for the Doctorate in Educational Sciences of the University of San Buenaventura - Medellín, line of research: Cultural Studies and Contemporary Languages of the ESINED research group. Here we deal with the process of epistemological contextualization of the concept of experimentation, using authors of the philosophy of difference and seeking an intersection with research-creation. This motivates a methodical way of proceeding that investigates other ways of prolonging literature as experimental writing, that is to say: minographic writings. This type of aesthetic production allowed the deployment of a series of methodical actions to perform along with the bodies that were present in the city of Medellín, already inhabiting existential places and later becoming different bodies and subjectivities.
\end{abstract}

\section{Keywords}

City; bodies; minographic writings; experimentation and research-creation

\section{Résumé}

Cet article est issu de la thèse de doctorat « Formation des subjectivités : Écritures minographiques des corps dans la ville », présentée pour le doctorat en sciences de l'éducation de l'Université de San Buenaventura - Medellín, axe de recherche : Études culturelles et langues contemporaines du groupe de recherche ESINED. Il s'agit ici d'aborder le processus de contextualisation épistémologique du concept d'expérimentation, en faisant appel aux auteurs de la philosophie de la différence et en cherchant une intersection avec la recherche-création. Cela motive une démarche méthodique qui explore d'autres manières de prolonger la littérature comme écriture expérimentale, c'est-à-dire les écritures minographiques. Ce type de production esthétique a permis le déploiement d'une série d'actions méthodiques à effectuer avec les corps présents dans la ville de Medellín, habitant déjà des lieux existentiels et devenant plus tard des corps et des subjectivités différents.

\section{Mots clés}

Ville ; corps ; écritures minographiques ; l'expérimentation et la recherche-création 


\section{Resumo}

O presente artigo é um desdobramento da tese doutoral intitulada, Formação de Subjetividades: Escritas Minográficas dos Corpos na Cidade, a qual está inscrita no Doutorado em Ciências da Educação da Universidade de San Buenaventura - Medellín, linha de investigação: Estudos Culturais e Linguagens Contemporâneas do grupo de pesquisa ESINED. Neste artigo, nos ocupamos do processo de contextualização epistemológica do conceito de experimentação a partir dos autores da filosofia da diferença, em intersecções com a investigação - criação, o qual motiva uma maneira metódica de proceder que indaga por outras formas de fazer continuar a literatura como escrita experimental, ou seja: as escrituras minográficas. Este tipo de produções estéticas, permitiram desdobrar uma série de ações metódicas para criar com os corpos que fizeram presença na cidade de Medellín. Uns corpos que habitaram lugares existenciais para devenir outros corpos e subjetividades.

\section{Palavras chave}

Cidade; corpos: escritas minográficas; experimentação e investigação-criação

\section{T apuchi rurai, imasa tapuchiita katichingapa ruraita chasallata}

\section{Katichingapa ruraita chasallata kilkaita}

\section{Maillallachiska}

Kaipi kachariska pangapi kilkaskata chi sumukumi iachaikudiru Universidad de San Buenaventura - Medellin Sutimanda. Sug mailla iacha runakuna ESINED. Suti apachinaku. Tapuchispa ruraspa mailla mailla kilkaspa Munanaku iachachinga, imasami nukanchi kikinta pangapi churanga. Chasallata sakinaku sug ruraikunata Uchullakuna katichingapa.

\section{Rimangapa Ministidukuna}

Chasa suti kausadiru; nukanchi kikin; kilkaska; rurai kallarii- tapuchi kausaita; nukakikin rurai kallariska 


\section{A manera de introducción}

Nuestra única orientación ha de ser una preparación a la experimentación. Y esta preparación consiste en no ser imitativos, en no juzgar, en no interpretar mediante las categorías generales de lo que está bien o mal; esto es, se trata de no reducir la experiencia a lo que se nos da socialmente como ya conocido. Puesto que no sabemos qué puede nuestro cuerpo, de qué afectos es capaz, hasta dónde puede llegar nuestro territorio, hay que probar.

(Deleuze, 1990 / Larrauri, 2015. p. 56)

En el presente artículo titulado investigar-crear: por unos modos de acontecer en la investigación con arte y literatura, ponemos al encuentro de la investigación-creación con lo que el filósofo francés Gilles Deleuze nos expresa en el epígrafe anterior, cuando en sus palabras se percibe el eco del pensamiento de Baruch Spinoza en la evocación de un cuerpo que primero hace, es y se prepara para la experimentación; $y$, segundo, no conoce de qué es capaz y de los alcances que puede tener. Dichas reflexiones se despliegan de la tesis doctoral titulada, Formación de Subjetividades: Escrituras Minográficas de los Cuerpos en la Ciudad, desde donde nos ocupamos del proceso de contextualización epistemológica del concepto de experimentación en entrecruces con la investigación-creación, lo cual motiva una manera de proceder que indaga en otras formas de hacer continuar la literatura, para el caso, las escrituras minográficas, como unas producciones estéticas encaminadas a crear con los cuerpos que se hacen presentes en la ciudad; es decir, que habitan lugares existenciales minoritarios o excluidos para devenir otros modos de existencia.

La manera como se teje la relación investigación-creación y experimentación es, en primer lugar, desde el agenciamiento del pensamiento de algunos filósofos relevantes en la manera en que en esta experiencia investigativa entendimos lo metódico. Y, en segundo lugar, haciendo que la escritura hilvane los diversos momentos en que se desarrolla el método (exponerse, pensarse y crearse) para con ello dar cuenta de cómo se concibe el método desde su construcción y su proceder en esta investigación. Vale la pena aclarar que, si bien hay reflexiones desde la filosofía y la estética sobre qué se entiende como investigación-creación, en la investigación doctoral prestamos atención a las herramientas propias en la configuración de nociones teóricas que sean objeto de reflexión en lo concerniente a la investigación con arte y literatura desde líneas de pensamiento y autores cercanos a las filosofías de la experiencia y de la diferencia y, hacer referencia desde estas coordenadas epistemológicas de la investigación-creación como un campo de disensos que no logra (de manera afortunada) una unívoca concepción de verdad.

En este sentido, los movimientos teórico-conceptuales $y$, de manera especial, los metódicos que se exponen en este texto, han trasegado por estas filosofías en clave educativa y por autores que ven en el arte y la literatura maneras de resistencia y creación que proponen giros a tradiciones, metodologías, discursos y verdades históricas. Ahora, los autores, por asuntos de agenciamiento y consonancia en sus propuestas filosóficas, los hemos pensado de la siguiente manera: Línea de pensamiento desde la filosofía de la diferencia, la experiencia y la multiplicidad: Friedrich Nietzsche (2006), Etienne Souriau (2017), María Zambrano (1996), Gilles Deleuze (1993), Isabelle Stengers (2014), Michel Onfray (2014), Jaques Ranciere (2002), David Lapoujade (William James) (2017), Miguel Morey (2007), Erin Manning y Brian Massumi (2016). Línea de pensamiento desde la filosofía para pensar la ciudad, el caminar y el viajar: Walter Benjamin (2004), Fernando González Ochoa (2018), Michel Foucault (2010) José Guillermo Ánjel Rendón (2014), Jean Luc Nancy (2002), y Claudia Arcila Rojas (2016). Y la línea de pensamiento para pensar la relación entre el arte, la literatura menor, lo minoritario y la experimentación: Gilles Deleuze, Carmelo Bene (2003), Peter Pal Perbart (2009) y Eduardo Pellejero (2014). En breve, el propósito de este artículo consiste en centrar la mirada en las escrituras minográficas como producciones estéticas derivadas del método pensado para esta investigación: investigación-creación en diálogo con las experimentaciones con el propio cuerpo en diversos espacios de la ciudad de Medellín.

\section{A propósito del método}

Es con Deleuze que la experiencia se asume como experimentación y no exclusivamente como interpretación, porque interesa, según lo aborda en Conversaciones (1992), prepararnos para experimentar. Lo cual consiste en no ser imitativos, en no juzgar y en no interpretar mediante las categorías generales de lo que está bien o mal (Deleuze, 1992). Para Deleuze la experiencia no debe ser reductible, se trata ante todo de no reducir la experiencia a lo que se nos da socialmente como ya conocido, porque el cuerpo para él mismo es una máquina (sin órganos) del que no sabemos cuáles son sus alcances, y hasta dónde puede llegar (Deleuze, 


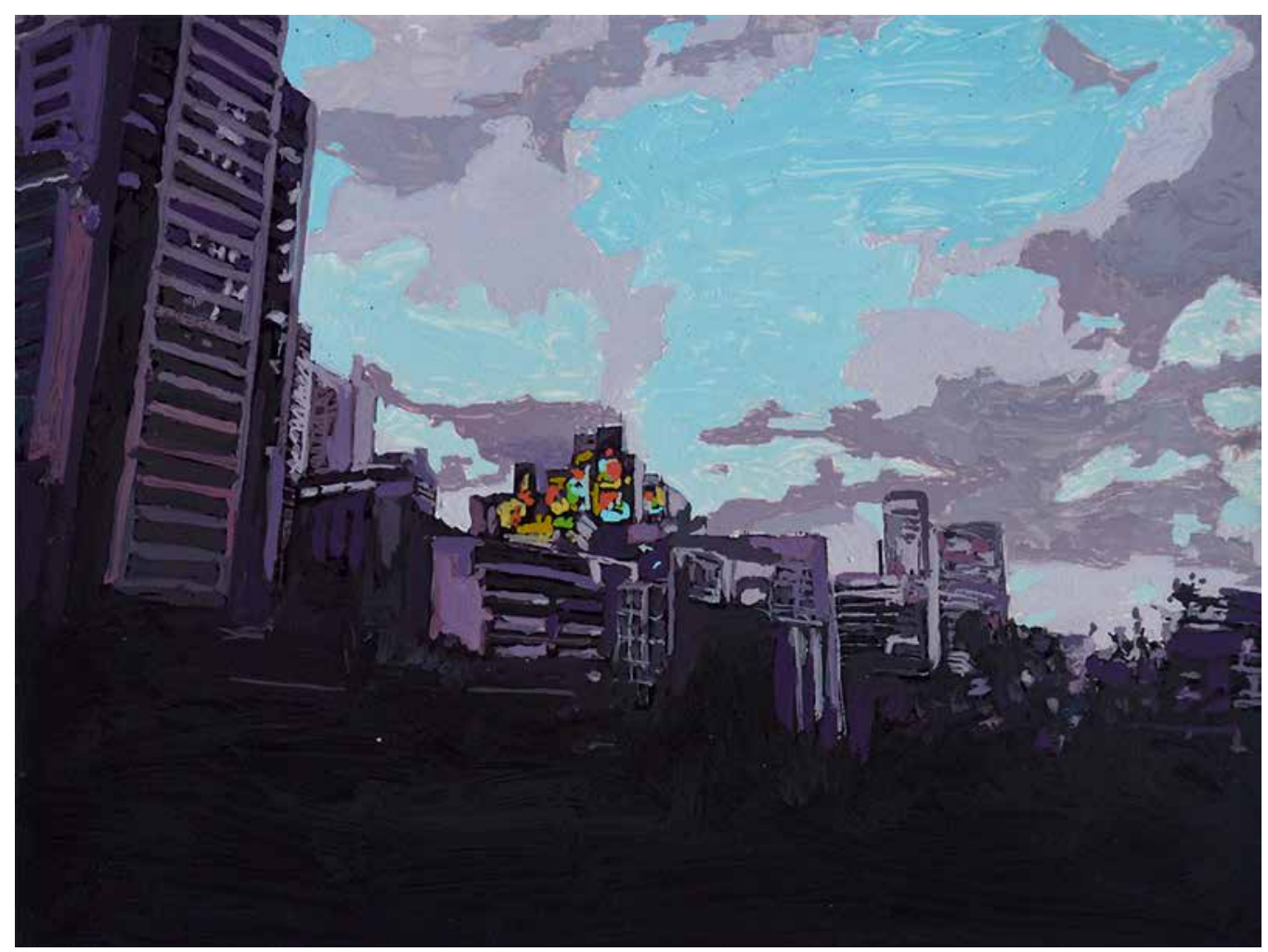

Imagen 1. Experimentación en la Ciudad (20 de abril de 2019).

1992). Esto es importante saber, en primera instancia, en una relectura de la obra de Baruch Spinoza donde se toma como potencia el cuerpo para apostarle a la invención de los materiales de producción de lo humano.

En este sentido, es relevante decir que el método investigación-creación lo hemos concebido en relación con la idea de experimentación que propone Deleuze y en tal sentido es interesante preguntarnos por la formación de subjetividades desde las escrituras minográficas de los cuerpos en la ciudad de Medellín. Esto a la vez que se reflexiona y conceptualiza sobre tales cuerpos que son producidos en y por la ciudad. Aparecen, desaparecen y reaparecen modos de existencia o formas de subjetividades que contribuyen acerca de lo que se entiende como lo humano en la contemporaneidad ${ }^{1}$.

A continuación, daremos un recorrido por los momentos del método de investigación para clarificar su proceder metódico; luego, haremos unas precisiones teóricas sobre las minografías o las escrituras minográficas en tanto producciones estéticas derivadas del método; $y$, al final presentaremos algunas de ellas en concordancia con la investigación-creación.

1 Lo contemporáneo lo comprendemos en relación con los autores y líneas de pensamiento señaladas. Tiene que ver más con unas formas de pensar y no solo con una temporalidad determinada.

\section{Momentos del método de investigación- creación}

El método lo compusimos en tres momentos que se tornaron simultáneos, paralelos, rizomáticos, mas no secuenciales ni jerárquicos, ni mucho menos ordenados desde una lógica de verticalidad o arborescente. Es decir, de la misma manera que Medellín como territorio de experimentación no tiene salidas, entradas o rutas de intervención trazadas con anterioridad, el método no obedeció a parámetros a priori para crearse a sí mismo. Valga decir que este modo de entrar en la relación con los espacios se sustrajo de la manera como Deleuze y Guattari abordaron la obra literaria de Kafka en el texto Kafka por Una Literatura Menor (1978). El método requiere, entonces, un cuerpo que hace experimentación en la ciudad con la intención de producir a través de unas escrituras minográficas, lugares de creación de modos de existencias en la actualidad; es decir, la indagación sobre subjetividades contemporáneas.

En este sentido, pensamos en tres momentos que hicieran posible la experimentación ${ }^{2}$ con el cuerpo en

2 La experimentación se asume en esta tesis doctoral como parte importante del método. El encuentro de esta con el método de investigación-creación, posibilita pensar las relaciones entre lo experiencial y teórico como una experiencia que no es fragmentada. 


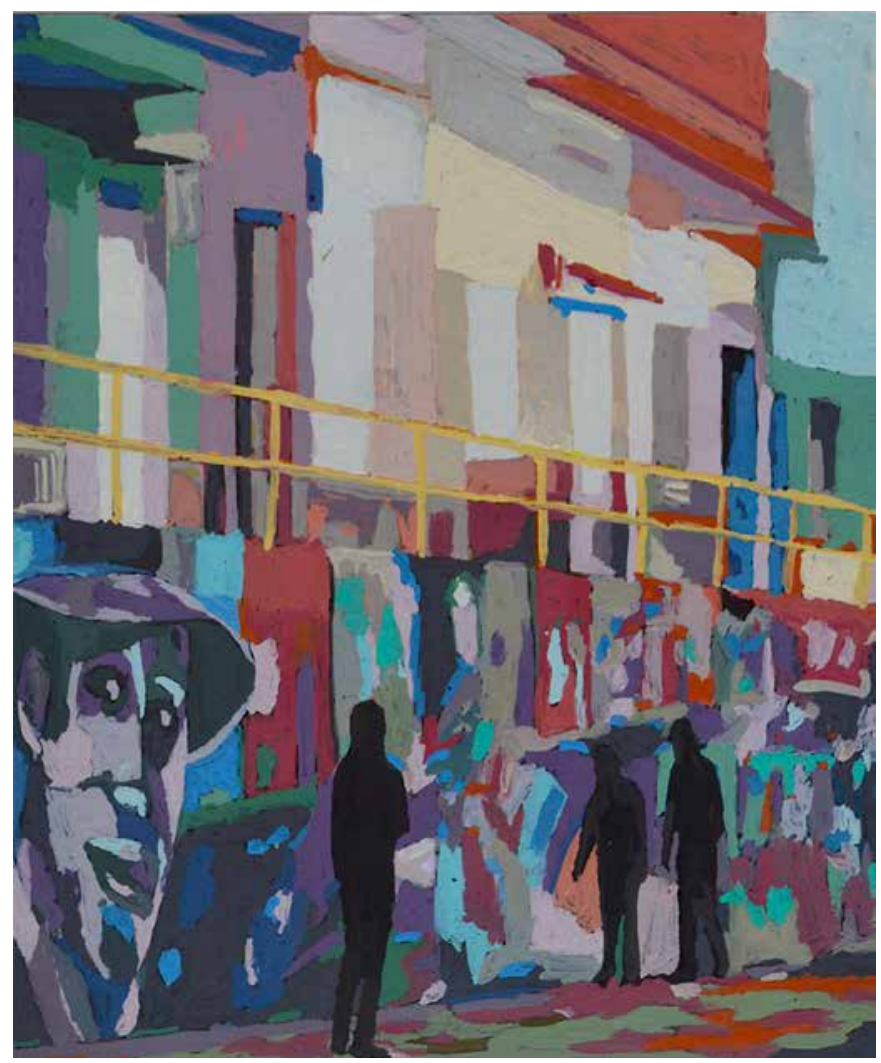

la ciudad, la reflexión y la producción de diversos tipos de cuerpos dando paso a las escrituras minográficas, desde el: exponerse, pensarse y crearse.

\section{Exponerse $^{3}$}

... realizar una serie de recorridos por la ciudad para demarcar lugares de lo menor. Y capturar sus trazos en forma de palabras, escrituras, colores, formas, entre

otras.

Los momentos del método no se dieron de manera anticipada a la experimentación. El encuentro con la ciudad fue posible por la aparición de trazos y rumbos desde lugares teóricos y epistemológicos que, a medida que avanzamos en los seminarios, círculos doctorales, simposios y pasantías permitieron el encuentro con líneas de pensamiento desde la filosofía y otros saberes en torno de los conceptos de experimentación (Deleuze, 1990 / Onfray, 2014), cuerpos, subjetividad(es), y, la ciudad; esta última rastreada desde las coordenadas teóricas que nos proporciona Foucault al considerarla como un gran espacio de espacios donde se configuran desde el encuentro de los cuerpos con

3 El exponerse implica el decir la experiencia con las ciudades, con los cuerpos, con los muros.
Imagen 2. Viajar por la comuna 3 de Medellín (15 de junio de 2018)

estos devenires y potencia de creación de heterotopías "espacios diferentes-otros" (Foucault, 2010, p. 71).

Encuentros académicos en el seminario de línea: estudios culturales y lenguajes contemporáneos ${ }^{4}$ posibilitaron pensar que la teoría no necesariamente se da por separado de las experiencias ni de las sensibilidades presentes en los diversos espacios académicos del doctorado y; de manera especial, en el trabajo de campo o -para la investigación doctoral en menciónen las experimentaciones. De este modo, la teoría y la práctica no se asumieron por separado, sino como un todo que permitió que la propuesta teórica, la experimentación como parte del método, el tema de la tesis (formación de subjetividades en las escrituras minográficas de la ciudad) y demás aspectos importantes

$4 \quad$ La línea de investigación estudios culturales y lenguajes contemporáneos del Doctorado en Ciencias de la Educación de la Universidad de San Buenaventura - Medellín, experimenta e indaga en las relaciones que se pueden dar entre los cuerpos, los espacios y las producciones artísticas que, en el interior de la línea, se nombran lenguajes contemporáneos. En el caso de la tesis doctoral titulada: Formación de Subjetividades: Escrituras Minográficas de los Cuerpos en la Ciudad, el encuentro entre las artes visuales y la literatura se constituyeron en una potencia para indagar en la formación de las subjetividades, dado que también hubo encuentros con la filosofía, de manera especial la filosofía de la experiencia y la filosofía de la diferencia. 
de la investigación se movieran y configuraran poco a poco hasta el punto de afectar tanto la tesis como el propio cuerpo.

De esta manera, para investigar-crear cobró sentido pensar en el concepto de cotidianidad (De Certeau, 1996). Este aparece como potencia creadora de los tránsitos que nos permitieron ver en el desarrollo de la investigación y del habitar la ciudad el lugar para agenciar y disponer los materiales conceptuales que permitieran la potencia de creación. Así, dispusimos un educar de la mirada y del cuerpo como un todo sensible para capturar realidades en tanto fuerzas de creación de lo otro; develar-crear desde trazos, formas, palabras, colores, sonidos, entre otros, los diversos tipos de cuerpos y subjetividades de los espacios de la ciudad que fueron objeto de las experimentaciones.

En la tarea de pensar dichos espacios de experimentación, hubo autores de la filosofía que desde sus líneas de pensamiento nos permitieron agenciar teoría y experiencia en la escritura de los primeros trazos de la tesis. Por ejemplo, Walter Benjamin (2004), Fernando González (2002), Michel Foucault (2010) y Jean Luc Nancy (2013) fueron referentes importantes para la producción de la escritura y de un pensamiento acerca de los cuerpos en la ciudad que, en las escrituras minográficas, pudo encontrar una manera propia de aparecer, desaparecer, reaparecer en esos modos de existencia que fueron configurando la formación de subjetividades y de la misma ciudad como una heterotopía vital de dichos modos de existir. Desde esta perspectiva, las relaciones y encuentros que se producen entre los cuerpos y los espacios de la ciudad configuraron lo que, acompañándonos de Deleuze, se constituye en una experiencia de entres dinámica y potente para darle lugar a lo insospechado o lo que está por venir (Deleuze, 1996).

Con base en lo anterior, viajar por la ciudad de manera desprevenida como experimentación, nos fue mostrando que los espacios son potentes en tanto afectan y pueden afectar a los cuerpos. Lo que interesa allí, entonces, es lo que se produce en el encuentro entre los cuerpos y los espacios: exponerse con el cuerpo en el espacio de ciudad, en sus recorridos, demarcando lugares y capturando trazos en formas de palabras, escrituras, colores y formas para, posiblemente, producir otros cuerpos.

\section{Pensarse $^{5}$}

...poner en tensión los movimientos subjetivos que transitan en la ciudad para dar paso a la creación.

La relación que Deleuze y Guattari establecen entre el arte y la filosofía es que ambas experiencias se conectan cuando acceden al lugar de la creación, la primera de perceptos y la segunda de conceptos (Deleuze y Guattari, 1993). Crear palabras, nuevas formas de nombrar $y$, en un trabajo de exigencia mayor con el pensamiento, crear conceptos, se corresponde con una manera de pensar que en una investigación es necesario arriesgarse a entrar en los terrenos de la creación no solo de artefactos, sino también de pensamiento desde lo que Deleuze señala como principal tarea del filosofar. El filosofar entonces, podríamos decir en conexión con Althusser, se corresponde con la posibilidad de desear y, desde una perspectiva materialista, vivir la experiencia y la práctica que "proviene del mundo real y produce, quizá sin saberlo, efectos concretos en este mundo" (Althusser, 2015, p. 34). De esta manera, la conexión entre teoría y práctica en la tesis se pensó en la relación que se establecen entre ambos lugares de conocimiento. No hubo un lugar de subordinación entre la una y la otra, por el contrario, ambas se fueron configurando a partir de lo que la misma investigación iba trazando como potencia. En este sentido, los referentes teóricos no se constituyeron en máximas inquebrantables, sino que su preponderancia radicó en poder pensar con los autores las particularidades que la experiencia iba presentando y, en ningún caso, proceder desde la óptica del ideal o del a priori, ni mucho menos considerarlo incuestionable.

Los trazos teóricos se agenciaron a líneas de pensamiento de la filosofía de la diferencia y de la experiencia, y desde allí se realizaron movimientos epistémicos que, en un momento avanzado de la investigación, permitió crear las escrituras minográficas. En este orden de ideas, las experimentaciones produjeron registros desde la imagen, los trazos y colores, la captura, visibilización y creación de formas de nombrar modos de existencia. Esto, en clave educativa, permitió a la vez hablar de la formación de otras subjetividades presentes en la ciudad contemporánea $y$, desde una mirada múltiple: lo ético, lo político y lo estético para aportar 
a las humanidades y a las ciencias de la educación un lugar "otro" de enunciación de lo humano.

Los diversos tipos de cuerpos que las minografías produjeron, en tanto sensibilidades capturadas en las experimentaciones, se produjeron desde lo que en la tesis se nombró cuerpos múltiples. Estos cuerpos múltiples se pensaron desde la heteronimia que se crea en diversas formas de cuerpos, estos son: cuerpos anfibios, cuerpos topos, cuerpos pájaros y cuerpos insectos. Estos términos extraídos del campo de la biología animal se constituyen en una forma análoga de nombrar formas sensibles de lo humano en los cuerpos que habitan la ciudad y sus lugares del discurrir de la cotidianidad; es decir, en calles, avenidas, parques, muros, bares, hoteles, entre otros espacios de vitalidad que pusieron en tensión los movimientos subjetivos que transitaron la ciudad, y, así fuimos dando paso a la creación.

\section{Crearse $^{6}$}

... componer escrituras minográficas que capturan tipos de subjetividades de los cuerpos que habitan, aparecen, desaparecen y reaparecen en la ciudad de Medellín.

Las escrituras minográficas, como aquellas que nos permitieron encontrar-inventar nuevos lugares para decir, echando mano de acciones, palabras, sensaciones y modos de existencia, como una manera de pensamiento en devenir. Unas escrituras de potencia ética, estética y política: una política de lo sensible en palabras de Ranciere (2002). Diríamos para el caso, una escritura de lo sensible que se pensó en la reinvención constante del nombrar y del percibir cierta realidad. En este sentido, lo sensible establece un vínculo entre los cuerpos y el pluriverso que habitan desde un accionar inmanente. Es una experiencia que el cuerpo conecta con otros modos de existencia y con los afectos que entre este y el mundo se producen. Lo sensible implica sensaciones, las cuales podríamos pensarlas como fuerzas que actúan sobre el cuerpo de manera intempestiva, generan afectos y su aparición no es de dominio previo.

El minografiar como escritura de lo sensible hilvanó posibilidades para experimentar la formación en diversos lugares: marginados, limítrofes y minoritarios, esta escritura de lo sensible que contiene lo político, trazó posibles rutas epistemológicas que dijeron a la educación desde la multiplicidad de cuerpos y subjetividades. Más adelante en el texto, se enunciará la composición teórico-epistemológica del concepto: Minografía como una escritura menor-sensible, a la vez literáfica (de literafía) porque no se escinde de manera absoluta de la producción literaria, está en un constante ir saliendo, y porque tal producción tiene sus bases en la filosofía; es decir que los encuentros con la literatura lo son también con la filosofía. Para minografiar, entonces, tuvimos como punto de partida los encuentros, centrados en la experiencia con lo singular para experimentar la vida en la cotidianidad y continuar contribuyendo a la reconciliación del pensar filosófico con el pensar cotidiano; la reconciliación del juglar, el aedo, el viajante, el caminante, el ciudadano a pie con el filósofo.

En este sentido, las minografías, se produjeron en dos momentos: un primer momento referido a su devenir epistemológico, es decir, estuvimos atentos a la historicidad del concepto. Así entonces, este se derivó de los intereses por obras literarias que en su momento denominamos literaturas particulares, por haber entre ellas asuntos comunes en relación con lugares de enunciación que entraban en tensiones con morales dominantes. Dichas literaturas fueron pensadas por diversos académicos e intelectuales de las humanidades y de la educación de Latinoamérica desde los siguientes conceptos: excluida, sospechosa, marginal, diaspórica, embólica, perturbadora y de exilio. Luego, durante la pasantía a las ciudades de Porto Alegre y Pelotas en Brasil, nos encontramos en esta última con el concepto de literatura menor (Deleuze y Guattari, 1978), el cual, desde sus características más relevantes: lo político, lo colectivo y lo desterritorializante, nos permitió abordar las literaturas particulares a partir de un único concepto, lo cual nos dio un margen de maniobrabilidad mayor y así no lidiamos con siete conceptos en la investigación. Ahora, el agenciamiento de las literaturas particulares con el concepto de literatura menor ${ }^{7}$ no fue forzado, se pudo realizar porque las literaturas particulares poseen alguna de las tres características de la literatura menor, es decir una literatura: desterritorializante, colectiva y política.

Así entonces, continuamos trabajando con el concepto de literatura menor, lo cual era viable, pero que, desde la perspectiva del mismo Deleuze, no implicaría un 
riesgo en la creación de conceptos. La otra posibilidad fue poner en tensión y experimentación dicho concepto y estar atentos a los puntos de fuga que la experiencia propiciaba. El movimiento conceptual que se generó fue el de no pensar la literatura menor o las pequeñas literaturas (Kafka, 1911) desde los estudios literarios tradicionales ni sobre obras específicas de autores como lo hicieron los filósofos franceses, Deleuze y Guattari, en Kafka Por una Literatura Menor (1978), sino ver en la ciudad y en los cuerpos que la habitaban, la potencia de nombrar y expandir la comprensión de lo literario sobre otras texturas y sensibilidades especiales de lo humano, como un asunto que en la contemporaneidad trasciende al libro y nos lleva a pensar que la formación de las subjetividades también es algo que se puede ver en la relación que entre cuerpos y espacios urbanos se teje y que fue potente en la investigación, ya que se piensa en conexión con lo educativo en tanto la formación de los cuerpos acontece en todos los espacios donde estemos, más allá, incluso de lo institucional. Así entonces, es a partir de escrituras minoritarias: escrituras minográficas que se nombra lo que desde lugares dominantes no se ha nombrado; es allí donde estas minografías como producciones menores aparecen como concepto que traza otras conexiones en el ámbito de la formación de las subjetividades de los cuerpos en la ciudad, a la vez que se escinden de los lugares comunes para nombrar. Lo menor emerge como un acto de resistencia (Deleuze y Guattari, 1978) en tensión con las formas dominantes del pensamiento, instauradas en el mundo, de manera especial, en los últimos siglos y arropadas desde lo que Guattari y Rolnik denominaron subjetividad capitalística (2006).

El segundo momento apunta a la producción de las minografías en las experimentaciones. En tal sentido, estas se crearon a partir de las experiencias que desde el método de investigación-creación se pensó ${ }^{8}$ para experimentar la ciudad con el propio cuerpo. La cuestión está en asumir la escritura como un ejercicio de registro del pensamiento en simultaneidad con lo que acontece en un tiempo presente y con lo que al propio cuerpo le va pasando, donde lo intempestivo es potencia para ver en la cotidianidad lo que normalmente no se ve. En este sentido, la bitácora para la investigación se constituyó en una de las herramientas para el registro de las experimentaciones, pero no solo esta fue importante, también lo fueron las fotografías y los registros audiovisuales

$8 \quad$ No hace referencia a algo sobre lo que se tuvo control absoluto o que haya implicado una construcción a priori. Corresponde mejor a una acción en gerundio, un pensar siempre en presente. que, en algunos casos, no en todos, hicieron parte de la experiencia del caminar por la ciudad, especialmente desde: luces, colores, formas, anocheceres, amaneceres, músicas, olores, toques, miradas, bailes, humos, bebidas, comidas, caminatas, pasajes, viajes, conversaciones, risas, entre otras sensibilidades.

En últimas, las escrituras minográficas o minografías son un quiebre metodológico. Desean como potencia, siguiendo a Deleuze (1996), crearse y visibilizar otras formas de subjetividades de la contemporaneidad. No son una sombra de la literatura menor; son un pliegue de este pensamiento deleuze-guattariano dislocado y puesto en la piel de la ciudad y los cuerpos que la habitan. Estas escrituras propician encuentros entre diversas formas de captura de la realidad, esto es, palabras, imágenes, fotografías, líneas, trazos y otras configuraciones del pensamiento.

Recordemos entonces que las epistemes a la manera como las entiende Foucault (1968) en Las palabras y las cosas implican una relación entre los conocimientos que se producen en una época y las condiciones históricas, todo ello desde un "marco de saber" (Foucault, 1968 , p. 7) que permite que comprendamos determinados conocimientos. En este sentido, las epistemes 0 marcos de saberes que se involucran con la producción del método de investigación doctoral se piensan desde una experiencia que en la actualidad considera la multiplicidad en los caminos de la investigación, que va más allá de los procederes dados desde el conocimiento científico y que ve en la experiencia misma la potencia para que cada investigación reclame su propio lugar de creación. Y, es que para investigar-crear-experimentar, se hace necesario prestar atención-registrar.

\section{Método-experimentación}

Todo método en relación con el arte debe ser una experimentación de los caminos por recorrer. Así lo piensa el profesor argentino Eduardo Pellejero ${ }^{9}$ (2014) cuando considera que la experimentación con las artes y con la literatura (para ser más precisos literatura menor) se constituye, de manera especial, en la posibilidad de establecer nuevos modos, rutas o caminos para la producción de obra y pensamiento. Sin embargo, en este ejercicio de pensar nuevas maneras de proceder con el arte, las relaciones entre la producción de la misma

9 Profesor de filosofía y literatura de la Universidad de Río Grande del Norte, Brasil. 


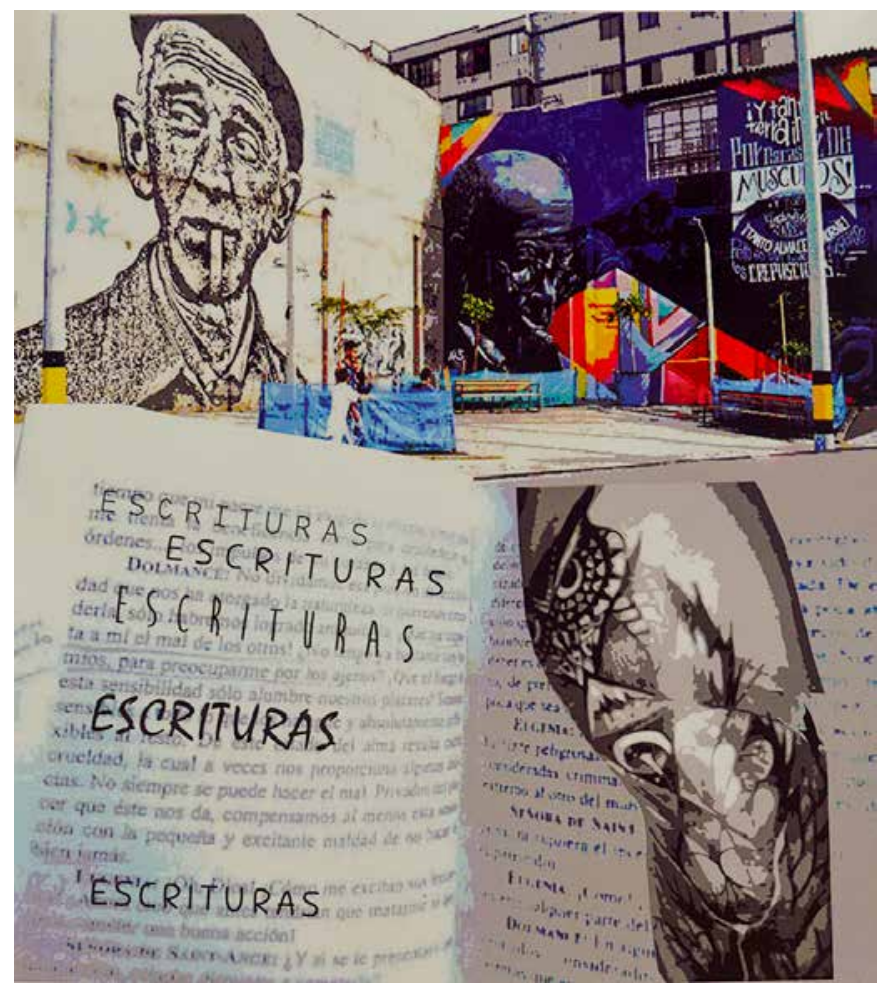

obra, la crítica (la academia) y la historia del arte se constituyen en los elementos que determinan históricamente el lugar y validación de los nuevos modos de hacer. Es decir, el lugar de la crítica ha tenido un lugar preponderante a la hora de decir si se valida o no un método, una tendencia, una obra, etcétera.

Desde esta perspectiva, los métodos de experimentación en las artes invitan a romper y revalidar los atributos propios y dogmáticos dados en el interior de las disciplinas, lo cual en el terreno de los estudios literarios parece que es más complejo por las lógicas y las estructuras epistemológicas de dicho campo estético. Así entonces, desde ciertas escuelas literarias hay mayor dificultad para pensar esta forma estética fuera de los marcos tradicionales de constitución de lo literario o de aquello que hace que la literatura sea la literatura, cuestión que ha sido un punto nodal para teóricos y críticos, tal es el caso de los formalistas rusos quienes ocuparon sus estudios por intentar establecer los elementos que constituyen la ontología de la literatura: la literariedad ${ }^{10}$.

A continuación, desplegamos el pensamiento de Pellejero con relación a cómo entender la

10 Los formalistas rusos, entre ellos, Roman Jakobson, tuvieron como especial interés abordar la literatura como un campo disciplinar, esto es de reflexión epistemológica. En este sentido, la ciencia literaria pretendió encontrar el ser de lo literario, lo cual se denominó literariedad.
Imagen 3. Cuerpos insectos, Escritura y la Ciudad (07 de agosto de 2018)

experimentación en la investigación con artes (investigación-creación), de manera especial desde la obra: Pensar a la intemperie: crítica expuesta al riesgo de la experimentación (2014), con el concepto de experimentación de Gilles Deleuze (1996).

En este orden de ideas, "la experimentación en arte constituye un objeto refractario para la crítica, que ve sus categorías cuestionadas, desbordadas por la propia naturaleza de su objeto (Pellejero, 2014, p. 510) y que en términos académicos suele ser un problema, dado que en las academias se establecen verdades que a través del tiempo pueden ser difíciles de refutar. En el ámbito de la academia, diversas posturas teóricas sobre un determinado campo del saber se tornan verdades irrefutables o ahistóricas como lo expresa Foucault en la Arqueología del Saber (2010) que, al estar en terrenos de ciencia o cercanos a la ciencia, parece que no pueden ser cuestionados. Ahora, en la historia también se ha demostrado que las contradicciones científicas son evidenciables, pero en realidad lo que importa es estar más atentos a los momentos de ruptura, novedad y discontinuidad y no preocuparnos por establecer verdades históricas irrefutables.

"Tal vez la experimentación no sea otra cosa que ese extrañamiento del arte con relación a sí misma" (Pellejero, 2014, p. 512), quizá no sea necesario que intentemos pensar que el arte deba ajustarse a las 
formas actuales de la academia o a las discusiones epistemológicas sobre si ingresa o no al campo de las epistemes. La experimentación con arte no requiere pensarse como la práctica a priori que, como una lista de chequeo, verifica si cumple o no cumple con cánones establecidos. En este punto, es preciso reiterar que la investigación-creación agencia desde la propia experiencia asuntos que están en un presente constante y que en la conexión con otros campos del conocimiento permite el extrañamiento de la propia experiencia y de los intermedios (los entres según Deleuze) que se asumen como fuentes de vitalidad. La potencia del extrañamiento de la propia experiencia es garante de movimiento, fugacidad y velocidad en los intersticios que ante tal extrañamiento se producen.

Y entonces, ¿cuál es el lugar del artista que asume su práctica con extrañamiento? pues el lugar es posible que se rastree en las coordenadas del tiempo por venir, más allá de los valores establecidos histórica y socialmente, pero a una velocidad e intensidad que no alcanza a consolidarse como verdad histórica.

Diríase que por vía de la experimentación los artistas de alguna forma se instalan en el futuro, o, mejor, en un tiempo propio, acrónico, anacrónico, y desde ese lugar extemporáneo trabaja el presente con los espectros de lo que todavía no es, conduciéndonos más allá de lo que nos es familiar (evidentemente, de ahí no se regresa, o no se regresa nunca de la misma forma) (Pellejero, 2014, p. 512).

La experimentación con artes es estar en el lugar de lo que aún no es, es el lugar de la utopía, pero no idealizada. Es el lugar que requiere de un cuerpo que se prepara para la experiencia, aunque no prevea lo que le acontezca en la experiencia, porque como lo señala Deleuze (1990) y lo retoma Larrauri (2015):

[...] nuestra única orientación ha de ser una preparación a la experimentación. Y esta preparación consiste en no ser imitativos, en no juzgar, en no interpretar mediante las categorías generales de lo que está bien o mal; esto es, se trata de no reducir la experiencia a lo que se nos da socialmente como ya conocido. Puesto que no sabemos qué puede nuestro cuerpo, de qué afectos es capaz, hasta dónde puede llegar nuestro territorio, hay que probar. (p. 56).

Este lugar del no juzgar y del no interpretar desde categorías dadas históricamente se establece como una prioridad para centrar la mirada en la experiencia misma y en lo que nos pasa allí. El prejuicio como forma preestablecida de un conocimiento se considera un obstáculo que limita la manera como nos podemos relacionar con la experiencia artística e investigativa, aunque reconocemos que esto no es algo que solo suceda en este terreno, sino que también sucede en otros campos del conocimiento.

En Crítica y Clínica Gilles Deleuze (1996) se ocupa de pensar asuntos relacionados con la creación de la literatura menor como una escritura de creación de la vida, allí hay un método. El mismo filósofo, en el prólogo de dicha obra, expresa que la creación es el problema cuando se piensa la escritura $y$, en tal sentido, todo método es escritura. Este pensamiento hace referencia a que "el problema de escribir es: el escritor (investigador) [...] inventa dentro de la lengua una lengua nueva, una lengua extranjera en cierta medida". (Deleuze, 1996, p. 3). Asimismo, el problema de escribir tampoco es separable de un problema de ver y de oír, un problema del cuerpo.

Se escribe entonces con el cuerpo y se escribe para inventar otras posibilidades de mundo, de expresión, de vivir. La literatura como una experiencia de lo menor tiene que ver con la vida, con otras maneras no establecidas hegemónicamente, y frente a esto el filósofo considera que la literatura menor en relación con la creación es ante todo una salud. "La salud como literatura, como escritura, consiste en inventar un pueblo que falta. Es propio de la función fabuladora inventar un pueblo" (Deleuze, 1996, p. 9). Reiteramos entonces que la percepción de muchas personas es creer que el mundo ya está dado. Crear es entonces poder tener la posibilidad de explorar otras formas de vida para resistir y deconstruir verdades que se nos han dado como irrefutables desde diversos dispositivos sociales de control. No obstante, esto de la literatura como una salud vital no consiste en la biografía individual de cada persona, "escribir no es contar los recuerdos, los viajes, los amores y los lutos, los sueños y las fantasías propios." (p. 7). En realidad, la literatura menor se vale de las singularidades para establecer asuntos que son colectivos, esta literatura es ante todo una literatura política, siempre está en relación con los otros, para no acallar, sino por el contrario, devenir un grito que desgarra.

Lo menor como creación en Deleuze tiene que ver con el devenir de la experimentación, pero es un devenir que está en relación con lo que históricamente no ha sido nombrado desde lugares dominantes, es un devenir-niño-homosexual-mujer-negro-animal... es un devenir-lo otro, es un devenir-método menor que se actualiza constantemente en las relaciones presentes 
que establece consigo mismo y con el mundo en el que se inventa. A manera de síntesis, la experimentación desde lo que proponen los autores mencionados Pellejero y Deleuze, en relación con lo que configuramos como método investigación-creación, no se constituye en el lugar para la crítica y la interpretación, pero sí en el lugar para la creación, el movimiento y la novedad; en el lugar para, a través de la propia experiencia, devenir en un extrañamiento de sí mismo y del mundo.

“(..) Y los viajes no se explican: se hacen. Aquí nada necesita ser explicado: ni los viajeros, ni el paisaje, ni el camino, ni la meta. Lo que interesa no son las peripecias de la aventura, sino el suceder interior de un filósofo que ve las cosas con una visión diferente, original."

(Arango, 2010, p. 12)

\section{Precisiones teóricas sobre las escrituras minográficas}

Y los viajes no se explican: se hacen, nos dice el poeta Gonzalo Arango en la introducción de la octava edición de Viaje a Pie (2010) del escritor y filósofo Fernando González Ochoa. A continuación, algunas precisiones teóricas para abordar las minografías que son, ante todo, unas producciones de la experiencia que capturan desde los trazos, las formas, los colores, las imágenes, las fugas, las palabras y los pliegues, tipos de subjetividades de los cuerpos que habitan la ciudad. Las escrituras minográficas son una apuesta por unas creaciones que centran la atención en lo que se produce entre los cuerpos y los espacios de la ciudad. Son escrituras de experimentación por ser producidas allí, pero también por indagar en la creación de propias elaboraciones poéticas para pensar vínculos entre lo filosófico y lo artístico que como ya señalamos es de vital importancia para el acto de creación. En este encuentro la escritura como narración de la experiencia se fuga de los preceptos de las teorías literarias tradicionales. Porque interesa que concibamos el narrar como un aspecto asequible a cualquier cuerpo, que requiere vitalizarse desde la experiencia sensible del existir y del habitar en la cotidianidad. El cuerpo que narra no es un narrador objeto de estudio de la narratología, no es un recurso narratológico, no sigue las lógicas establecidas; narra desde sí mismo. Dice desde la experiencia, por ser la manera que tiene para poder decir del mundo; no narra desde la idealización como lo establecido y absoluto, y en el decir de su experiencia puede crear estéticas que cuestionan, problematizan y resisten las formas dominantes de existir (a propósito de las minografías producidas con el nombre de anfibios y topos); es un narrador que dice de la experimentación con el propio cuerpo al minografiar. Minografiar como una acción de fuga, un constante salir, pero sin hacerlo del todo; inventar nuevas maneras para sortear su tránsito por dichos andamios teóricos en el hallazgo de posibles percepciones amorfas, es decir, aquello que, aun no tiene forma definitiva. Las minografías no son producciones autobiográficas en el sentido fiel de producción de la escritura del yo que los antiguos cultivaron (al respecto hay una revisión amplia desde Michel Foucault y el profesor Carlos Rojas Osorio). En ellas lo singular aflora por el encuentro que entre cuerpos se establece. Por el contrario, lo individual se escinde porque lo otro desde una mirada ética y política no remite a la exaltación de un yo autoral; por contraste, implica pensar la colectividad como una cuestión de singularidades y de diferencias, todo ello en la indagación acerca de las formas de subjetividad.

Minografiar es poetizar la realidad, no necesariamente por barroquizar la experiencia con recursos estéticos y figuras retóricas, sino por considerar la creación de otros lugares para decir, esto es, acciones, palabras, sensaciones y modos de existencia, como una manera de pensamiento en devenir. Es una escritura de potencia ética, estética y política: una política de lo sensible en palabras de Ranciere (2002). Diríamos para el caso, una escritura de lo sensible que se piensa en la reinvención constante del nombrar y percibir la realidad. En este sentido, lo sensible establece un vínculo entre los cuerpos y los espacios que habitan desde un accionar inmanente, entendido según Deleuze como la producción de deseo en uno mismo (Deleuze, 1990). Es una experiencia que el cuerpo conecta con otros modos de existencia y con los afectos que entre este y el mundo se producen. Lo sensible implica sensaciones, las cuales podríamos pensarlas como fuerzas que actúan sobre el cuerpo de manera intempestiva, generan afectos y su aparición no es de dominio previo.

Las minografías como escrituras de lo sensible hilvanan posibilidades para experimentar la formación en diversos lugares: marginados, limítrofes y minoritarios, estas escrituras de lo sensible que contienen lo político trazan posibles rutas epistemológicas que pueden decir sobre lo educativo en tanto nuestra formación acontece en todos los momentos y espacios donde estemos.

Lo sensible desde esta perspectiva tiene que ver con las conexiones que desde lo ético piensa la relación de los 


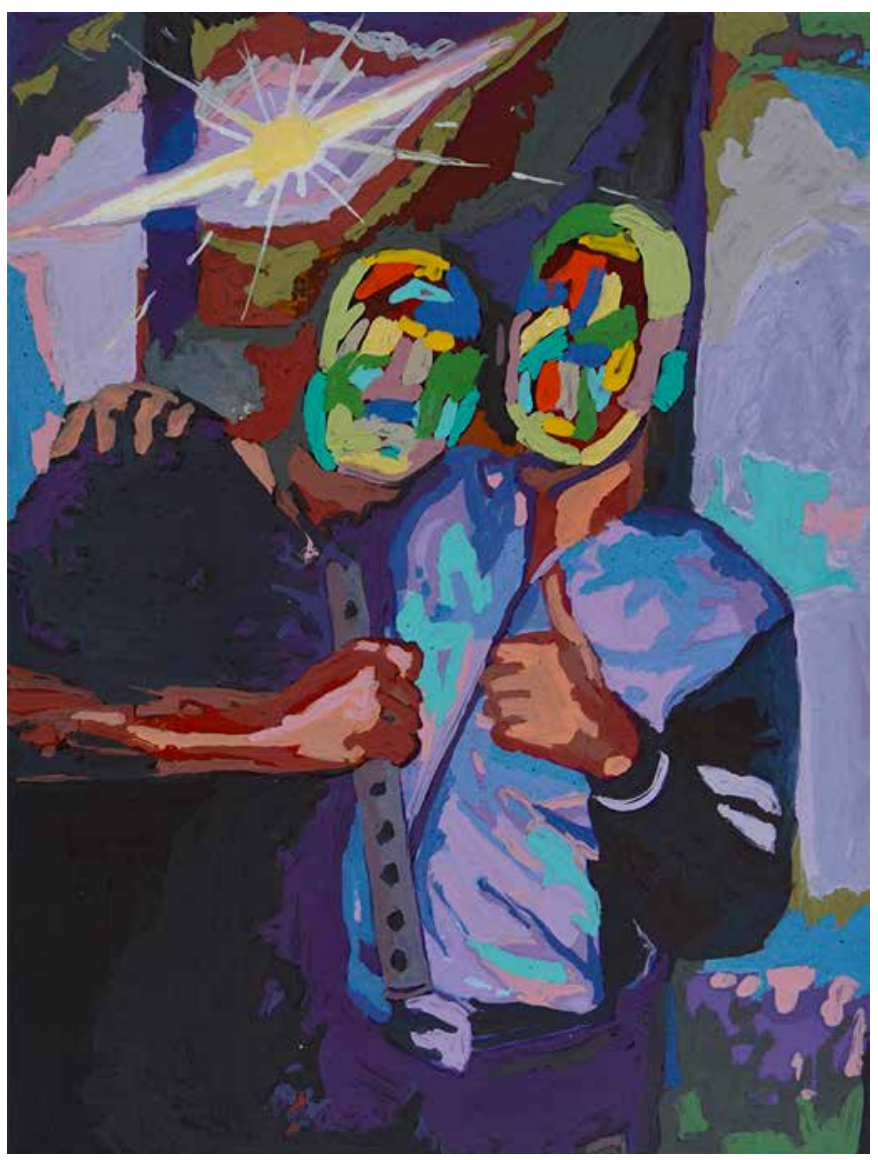

cuerpos en unos territorios determinados, o sea, la posibilidad de pensarnos como cuerpos sensibles. Las minografías no centran su mirada en las distinciones sociales, raciales, ideológicas ni sexuales. Es precisamente en ese quiebre con la tradición y la historia que lo sensible emerge como un asunto de reconocimiento y visibilización de diversas sensibilidades y modos de existencia. Esta escritura de lo sensible indaga en la formación de las subjetividades como un tema central, para pensar en las maneras y procederes que les atañe lo estético como un asunto de la producción en la configuración de los tipos de subjetividades. Asimismo, lo estético no desea elevarse a categorías de moldeamiento; por el contrario, se reinventa desde lo humano en la actualidad, ya que está pensada para transitar los propios senderos de investigación. Es una escritura menor-sensible que tiene sus bases en la literatura menor y en la filosofía de la diferencia. Estos encuentros se centran en la experimentación con lo singular para experimentar la vida en la cotidianidad y continuar contribuyendo a la reconciliación del pensar filosófico con el pensar cotidiano; la reconciliación del juglar, el aedo, el viajante, el caminante, el ciudadano a pie con el filósofo. Las escrituras minográficas son contingentes porque dicen que las cosas pueden ser de otras maneras posibles, lo cual es la prioridad en situaciones de contingencia, así pues, lo que se presenta es una provisionalidad epistemológica. En este sentido, no son necesarias como algo útil desde lo instrumental, porque lo necesario no admite otros modos. En ellas se considera que la vida humana, el mundo, las formas de vivir, entre otros aspectos relacionados con la formación de las subjetividades pueden devenir multiplicidad. Y es desde la multiplicidad que se tornan en producciones de entres y en ello está la posibilidad de no reducirse a la identidad, ya que el entre está en medio de dos o más identidades, pero al conservarse en dicha zona de márgenes no se reduce o se subordina ante estas, sean de un lado o de otro. El encuentro entre los cuerpos y la ciudad es lo que permitió el aparecer de multiplicidad de las minografías y posibles subjetividades. Ahora, esta escritura de entres, también es comprometida y expandida.

Comprometida porque desde sus preceptos ético-políticos asume el lugar de voz para la visibilización de los modos de existencia y los lugares minoritarios de la ciudad. Las minografías reivindican el lugar de la literatura menor que se compromete con los pueblos por venir en sentido crítico y clínico, a propósito de la obra de Deleuze como potencia de creación, con las minorías y con la justicia, entendida como la visibilización de modos de existencia dominados, silenciados, 


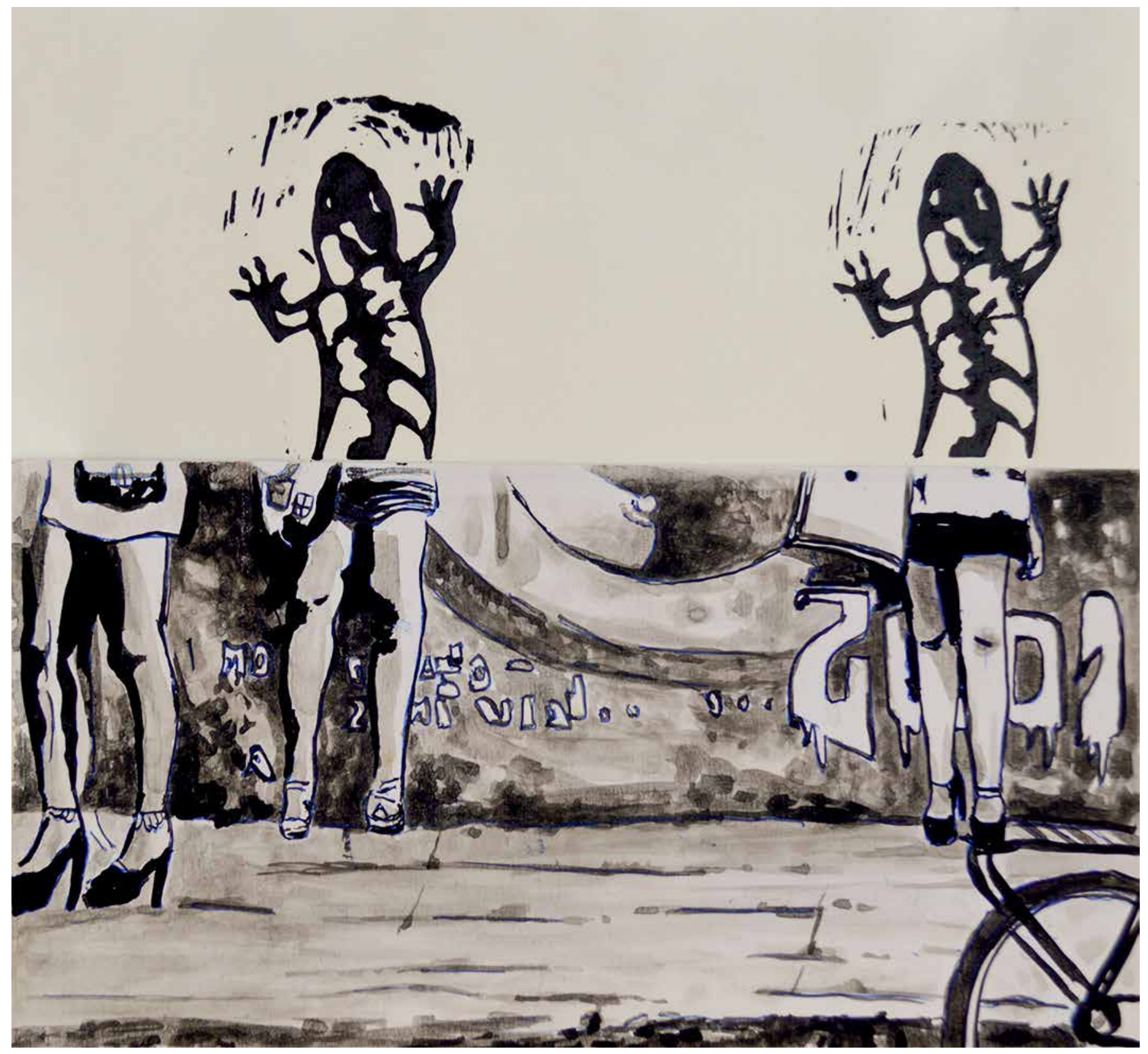

Imagen 5. Cuerpos anfibios (18 de agosto de 2018)

desaparecidos e ignorados (Deleuze, 1996). Esta escritura asume el compromiso como una deconstrucción de la idea tradicional del amor en tanto sometimiento y reconoce la importancia de existir para pensarnos desde y en el pluralismo'11(James, 2009). Tomando en cuenta lo anterior, estas escrituras se expanden a otras formas sensibles de producción de lo humano para desde diversos lugares de enunciación agenciar formas de producción estética como creación de lo humano en devenir constante. Como última precisión, estas escrituras de la multiplicidad se produjeron desde un pensar contemporáneo desde el cuerpo como centralidad del

11 Recomendamos rastrear este concepto en la obra: Un Universo Pluralista. Filosofía de la Experiencia de William James. acontecer. Quiere decir entonces, que las sombras del pensamiento del cuerpo fragmentado y de la razón desbordada no se supera de manera absoluta, pero sí se pone en crisis. La idea es estar saliendo constantemente de dicha lógica sin salir del todo de las sombras del pensar lo humano en la tradición. Lo importante entonces es mirar: ¿cómo persiste el pasado? ¿Cómo existimos con él? ¿Cómo lidiamos con estas fuerzas históricas de subjetivación? Y, ¿cómo nos relacionamos con estas tensiones? Porque se trata, en últimas, de un movimiento continuo y no de un punto de llegada. Se trata de una escritura de postradición: contemporánea. 
$Y$, es en este sentido que presentamos unas escrituras minográficas o minografías, producto de la creación con el propio cuerpo y del proceder metódico desarrollado en este artículo. Escrituras de formas minoritarias que nos permitió visibilizar modos de existencia que transitan por las pieles y pliegues de la ciudad en un mudar de pieles y transformación de los cuerpos que se adaptan a diversas atmósferas, climas y espacios de la ciudad. Entonces, presentamos unas escrituras minográficas sobre los cuerpos anfibios y los cuerpos topos.

(..)

(Atmósfera: luz natural - brisa suave)

¿Qué es un cuerpo anfibio?

Es un cuerpo que se adapta a diversas atmósferas.

Su captura del mundo se torna multiplicidad porque su sensibilidad se activa en otras coordenadas,

quizá no experimentadas en otros momentos, quizá experimentadas por supervivencia.

Es un cuerpo producido de manera especial en la ciudad.

Su relación con las heterotopías urbanas lo tornan anfibio y camaleónico.

La errancia le implica encontrar maneras de transitar por múltiples ecosistemas donde se le producen movimientos vitales.

Si lidiar implica hacerse cargo de los afectos: aquellas sensaciones intempestivas que se producen en los cuerpos, el cuerpo anfibio adapta su organismo a las particularidades de los ecosistemas.

El cuerpo anfibio que vive en errancia es un cuerpo constantemente en formación. Transita por la ciudad mudando pieles en un constante ir saliendo.

(Atmósfera: calles - alcantarillas - basureros el inframundo)

Cuerpos Topos

El cuerpo topo socaba constantemente atmósferas subterráneas.

A veces los cuerpos topos devienen anfibios, la diferencia radica en que los anfibios van y vienen por diversas atmósferas

y los topos corroen permanente por zonas marginales.

La vida de los cuerpos topos se produce en medio de la hipocresía moral de la sociedad.
Los cuerpos topos son errantes sociales. Muchos de los cuerpos topos son migrantes, su condición no les permite acceder a los mínimos básicos de supervivencia.

Latinoamérica es una tierra productora de toperas despreciadas por los dominantes.

Medellín, el Monstruo de Tentáculos, es también una guarida de topos.

\section{Referencias}

Althuser, L. (2017) Iniciación a la Filosofía para los no Filósofos. Editorial Planeta Colombia. Bogotá.

Arcila, C. (2016) El Cuerpo Sensible. David Le Breton. Ciencias Sociales y Educación, Vol. 5, № 9. Medellín.

Bene, C. \& Deleuze, G. (2003) Un Manifiesto de Menos. En Superposiciones. Ediciones Artes del Sur. Buenos Aires.

Benjamin, W (2004) El Libro de los Pasajes. Edición de Rolf Tiedemann. Ediciones Akal S.A. Madrid. Tomado de: https://tinyurl.com/unjbmz68

De Certeau, M. (1996) La Invención de lo Cotidiano. Universidad Iberoamericana. Cultura Libre. México.

Deleuze, G. (1990) Conversaciones 1972-1990.

Experimentaciones. Recuperado en: - (1996) Crítica y Clínica. Traducido por

Thomas Kauf Editorial Anagrama, Barcelona. (1978) Kafka Por Una Literatura Menor.

Ediciones Era S.A. México.

De Certeau, M. (1996) La Invención de lo Cotidiano. Universidad Iberoamericana. Cultura Libre. México.

Deleuze, G. (1990) Conversaciones 1972-1990.

Experimentaciones. Recuperado en:

https://tinyurl.com/t33ah9vr - (1996) Crítica y Clínica. Traducido por

Thomas Kauf Editorial Anagrama, Barcelona.

Deleuze, G y Guattari, F. (1978) Kafka Por Una Literatura Menor. Ediciones Era S.A. México. 
Foucault, M. (2010) La Arqueología del Saber. Editorial Siglo XXI. México D.F.

. (2010) Las Heterotopías. Ediciones Nueva

Visión. Buenos Aires.

González, F. (2018) Los Viajes o las Presencias. Fondo Editorial de la Universidad EAFIT. Medellín. (2010) Viaje a Pie. Fondo Editorial de la Universidad EAFIT. Medellín.

Guattari, F. y Rolnik, S. (2006) Micropolítica.

Cartografías del Deseo. Edición Traficantes de Sueños. Madrid.

James, W. (2009) Un Universo Pluralista. Filosofía de la Experiencia. Editorial Cactus. Buenos Aires.

Kafka, F. (1913) Diarios. Tusquets Editores, edición de Max Brod. Tomado de: https://tinyurl.com/k9nerfvf

Lapoujade, D. (2017) As Existências Mínimas. Edições N-1. São Paulo.

(2017) William James, A Construção da

Experiencia. Edições N-1. São Paulo

Larrauri, M. (2015) El Deseo Según Gilles Deleuze.

Editorial Frontera Digital. Madrid.

Manning, E. (2016) The Minor Gesture. Duke University Press Durham and London. Bogart, Georgia.

Morey, M. (2007) Pequeñas Doctrinas de la Soledad. Editorial Sexto Piso, S. A. de C. V. México.

Nancy, J. L. (2002) “El corazón de las cosas". En Un Pensamiento Finito. Anthropos Editorial. Barcelona.

Nietzsche, F. (2006) Ecce Homo. Editorial SKLA. Bogotá.

Onfray, M. (2014) "De la excepción o la máquina célibe”. En La Escultura de Sí. Errata Naturae Ediciones. Madrid.

Pal Perbart, P. (2009) Imagens do Nosso Tempo en Imagen Contemporánea: Cinema, T.V. documentário, fotografía, videoarte, games. Editora Hedra Ltda. Sao Paulo.
Pellejero, E. (2014) Pensar a la Intemperie: Crítica Expuesta al Riesgo de la Experimentación. Universidad federal do Rio Grande do Norte. Brasil.

Ranciére, J. (2002) La División de lo Sensible. Estética y Política. Salamanca: Consorcio de Salamanca.

(2009) Política de lo Sensible. Tomado de:

http://esferapublica.org/esteticapolitica.ranciere.pdf

Souriau, E. (2016) La Correspondencia de las Artes. Sexta reimpresión. Editorial del Fondo de Cultura Económica. México.

Stengers, I. (2014) Cosmopolitiques. Civiliser les Pratiques Modernes" en Stengers, Isabelle. Une autre science est possible. Manifeste pour un ralentissement des sciences (Paris, Editions La Découverte, 2013).

Stengers, Isabelle. "La propuesta cosmopolítica". Revista Pléyade 14 (2014): 17-41.

Zambrano, M. (1996) Filosofía y Poesía. Fondo de Cultura Económica. México D.F. (2011) Notas de Un Método. Editorial Tecnos, edición los especiales de la filosofía. Madrid. 